\title{
Bodo Ebhardt y los castillos españoles: notas sobre su obra de restauración y su pensamiento europeísta y pangermánico
}

Ignacio Javier Gil Crespo

\section{Centro de Estudios «José Joaquín de Mora»/Fundación Cárdenas}

\section{Fecha recepción 02.11.2015/ Fecha aceptación 07.03.2016}

\section{Resumen}

El arquitecto y restaurador alemán Bodo Ebhardt (1865-1945) viajó a España en 1930, donde recorrió y documentó, durante dos meses, algunos castillos y fortalezas representativos. En 1934 publicó la memoria de esta excursión como un cuaderno de viajes salpicado de dibujos, detalles y croquis. Este material lo empleará y reelaborará, apoyado en un importante trabajo de documentación bibliográfica actualizada en su momento, para el capítulo sobre la fortificación española en su enciclopé-

\begin{abstract}
The German restorer and architect Bodo Ebhardt (1865-1945) travelled to Spain in 1930, where for two months he documented several, significant castles and fortresses. In 1934, he published the record of this trip as a travel album containing many drawings, details and sketches made during his stay. He re-employed and re-elaborated this material, supporting it with current bibliographic documentation, in the chapter dedicated to Spanish castles in his encyclopaedic work Der Wehrbau Europas im
\end{abstract}




\section{Resumen}

dica obra Der Wehrbau Europas im Mittelalter (1939-1958). El artículo explica el controvertido y criticado pensamiento y actuación de Ebhardt en cuanto a la labor de la intervención en los monumentos históricos y sus ideas sobre la evolución de las formas y los elementos de los castillos europeos y españoles en particular a través de sus publicaciones.

\section{Palabras clave}

Castellología, historiografía, castillos, fortalezas, Edad Media, restauración arquitectónica

\section{Abstract}

Mittelalter (1939-1958). This article explains the controversy and criticisms surrounding his thinking on the efforts of intervention with regard to historical monuments and his ideas about the evolution of the forms and elements of the European, and particularly Spanish castles in his scientific publications.

\section{Key words:}

Castle science, historiography, castles, fortresses, Middle Ages, architectonical restoration 
El desconocimiento aparentemente generalizado en España sobre la figura y la obra - tanto de intervención sobre el patrimonio castrense alemán como de investigación y divulgación científica - del arquitecto Bodo Ebhardt insta a elaborar un estudio preliminar sobre este arquitecto e historiador de la arquitectura fortificada que no sólo restauró más de 50 castillos en Alemania sino que analizó y escribió sobre la arquitectura militar medieval europea. Entre los castillos que documentó y estudió se encuentran los españoles. En 1930, Bodo Ebhardt realizó un viaje por España recorriendo algunos de los principales monumentos militares de la Edad Media. Cuatro años más tarde publicó su cuaderno de viajes junto a un nutrido número de dibujos tomados durante su "paseo entre castillos" - Burgenfahrt- que forma la base de su capítulo sobre los castillos españoles dentro de su enciclopédica obra Der Wehrbau Europas im Mittelalter (1939-1958). ${ }^{1}$

El objetivo fundamental de este trabajo de investigación es ofrecer en lengua española una semblanza del arquitecto y restaurador atendiendo a su vida, obra de intervención sobre el patrimonio, actividad científica y pensamiento, así como de las críticas que recibió su actividad profesional y científica. Se analiza el viaje que realiza entre los meses de febrero y abril de 1930 por España y cómo estos datos, dibujos, detalles y fotografías se reelaboran unos años más tarde en la publicación sobre la fortificación medieval europea (Der Wehrbau Europas im Mittelalter), donde aflora - al igual que en otras muchas publicaciones suyas- un anhelo por una Europa pangermánica. Se explica su pensamiento estético - también político e ideológico - en cuanto a la restauración arquitectónica del monumento militar y su interés por la base científica del trabajo de conservación y restauración patrimonial.

Este trabajo no deja de ser unas notas para un estudio en profundidad posterior. Para su elaboración se ha seguido un método de documentación bibliográfica a través de diversas bases de datos y bibliotecas especializadas, como Regesta Imperii, Dialnet, ISOC, la Deutsche National Bibliothek, la Deutsche Burgenvereinigung, la Sächsische Biografie del Institut für Sächsische Geschichte und Volkskunde o la Biblioteca Tomás Navarro Tomás del Centro de Ciencias Sociales y Humanas del Consejo Superior de Investigaciones Científicas.

\section{Bodo Ebhardt y la restauración de los castillos}

La figura y la obra del arquitecto e historiador alemán Bodo Ebhardt no han tenido en España el peso ni la influencia de los que sí ha gozado en Europa. Se han utilizado en alguna ocasión sus dibujos y plantas, mas no se encuentran referencias entre la bibliografía específica. Bodo (Heinrich Justus) Ebhardt nació el 5 de enero de 1865 en Bremen y murió a los 81 años, el 13 de febrero de 1945, en el castillo de Markburg en Braubach que él mismo restauró entre 1899 y 1905 como sede de la Deutsche Burgenvereinigung (Asociación Alemana de los Castillos) (fig. 1).

El interés por los castillos por parte del arquitecto alemán nace en su época de estudiante de ebanistería en la Escuela de Artes Decorativas de Berlín siguiendo la profesión de

1. B. Ebhardt, Der Wehrbau Europas im Mittelalter. 3 vols Würzburg, Stollham, 1939-1958. 


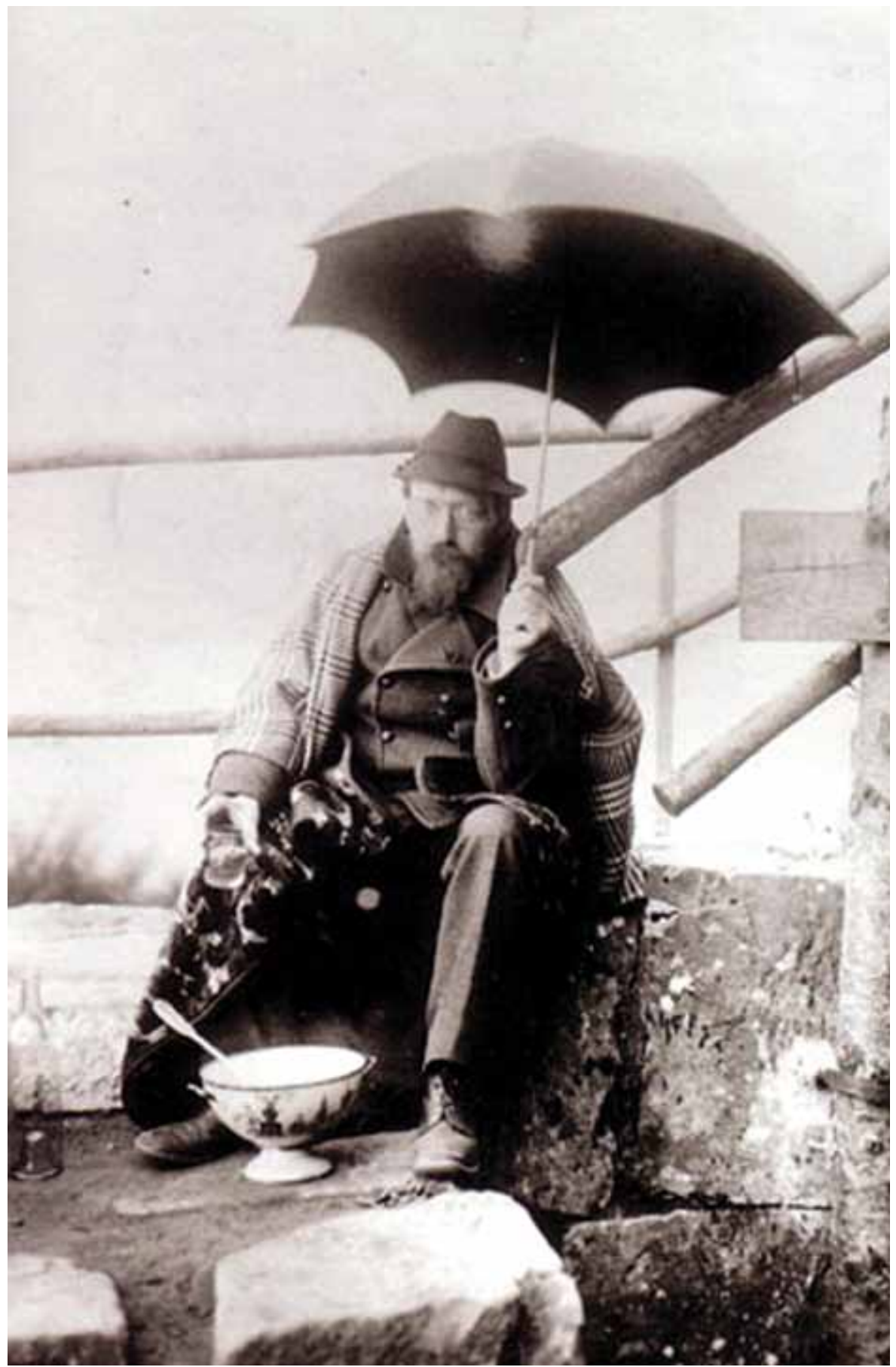

Figura 1. Bodo Ebhardt durante las obras de restauración de Hohkönigsburg (DBV/Inventaire Alsace, Francia) 
su padre, si bien al poco comenzó a trabajar como arquitecto. Esta formación inicial se notará en sus proyectos, pues diseña el mobiliario para los castillos que restaurará. Su actividad profesional se enfocó en la restauración de los castillos alemanes. Este trabajo se vio favorecido, en parte, gracias a su amistad con el emperador Guillermo II, quien lo nombró arquitecto de la Corte y arquitecto del emperador. ${ }^{2}$

Entre las más de 50 restauraciones de castillos ejecutadas bajo la dirección de Ebhardt —se denominó a sí mismo «el Restaurador (Wiederhersteller) de los Castillos Alemanes» ${ }^{3}$ - se encuentran los castillos de Marksburg, en Braubach am Rhein (1899-1905), de Hohköningsburg en Alsacia (1901-1908), de Hakeburg en Kleinmachnow (1906-1908), el de Grodziec en Silesia (1906-1908), de Neuenstein en Württemberg (1906-1914), de Veste Coburg (1906-1924), de Sallgast (1911-1912) o de Wommen en Turingia (1911-1913), entre otros. En el biocronograma de la tabla 1 se detallan los proyectos ejecutados por Bodo Ebhardt en relación con algunos aspectos biográficos relevantes.

\section{Tabla 1. Biocronograma de Bodo Ebhardt ${ }^{4}$}

\begin{tabular}{|l|l|l|}
\hline Año & Vida & Obra \\
\hline 1865 & Nace en Bremen & \\
\hline 1880 & $\begin{array}{l}\text { Estudios empresariales en Bremen y } \\
\text { Magdeburgo }\end{array}$ & \\
\hline $\begin{array}{l}\text { Se traslada a Berlín para estudiar en } \\
\text { el Kunstgewerbemuseum (Escuela } \\
\text { de Artes Decorativas) de Alexander } \\
\text { Schütz, completando su formación } \\
\text { de manera autodidacta }\end{array}$ & \\
\hline 1890 & $\begin{array}{l}\text { Abre su estudio de arquitectura en } \\
\text { Berlín }\end{array}$ & \\
\hline 1891 & $\begin{array}{l}\text { Se casa con Agnes (Krebs), nacida en } \\
1970\end{array}$ & \\
\hline 1892 & Nace su hijo Bodo & Villa Seibt en Berlín-Grunewald \\
\hline $1892-$ & & \\
1893 & & \\
\hline
\end{tabular}

2. M. Donath, "Ebhardt, Bodo Heinrich Justus," en Sächsische Biografie, Dresde: Institut für Sächsische Geschichte und Volkskunde, 2009.

3. R.R. Taylor, The castles of the Rhine. Recreating the Middle Ages in modern Germany, Waterloo, Ontario, Wilfrid Laurier University Press, 1998, 242

4. Elaboración propia según datos de Donath, op. cit. 


\begin{tabular}{|c|c|c|}
\hline $\begin{array}{l}1893- \\
1894\end{array}$ & & $\begin{array}{l}\text { Landhaus Ebhardt en Berlín-Grunewald } \\
\text { (vivienda propia) }\end{array}$ \\
\hline 1894 & & $\begin{array}{l}\text { Complejo residencial y comercial } \\
\text { "Wilhelmshof" en Groß-Lichterfelde, } \\
\text { cerca de Berlín }\end{array}$ \\
\hline 1894 & Nace su hijo Fritz & \\
\hline 1894 & & $\begin{array}{l}\text { Logierhaus "Fürstenhof" en Karlshorst } \\
\text { en Berlín }\end{array}$ \\
\hline $\begin{array}{l}1894- \\
1895\end{array}$ & & $\begin{array}{l}\text { Establos de los tintoreros. Villa en } \\
\text { Aachen- Burtscheid }\end{array}$ \\
\hline $\begin{array}{l}1895- \\
1896\end{array}$ & & $\begin{array}{l}\text { Casa Schröder-Poggelow en Berlín- } \\
\text { Tiergarten }\end{array}$ \\
\hline 1896 & & Jeques Villa en Berlín-Grunewald \\
\hline 1896 & & $\begin{array}{l}\text { Casa residencial Ebhardt en } \\
\text { Berlín-Tiergarten, Rauchstrasse } 13\end{array}$ \\
\hline 1899 & $\begin{array}{l}\text { Fundación de la Deutsche Burgenve- } \\
\text { reinigung }\end{array}$ & \\
\hline 1898 & & Monumento Sporting en Berlín \\
\hline $\begin{array}{l}1899- \\
1901\end{array}$ & & $\begin{array}{l}\text { Villa Langenscheidt en la colonia } \\
\text { Alsen, Berlín-Wannsee, Colomierstraße } 1\end{array}$ \\
\hline $\begin{array}{l}1899- \\
1900\end{array}$ & & $\begin{array}{l}\text { Villa Passow / Fulvio / Voss (hoy } \\
\text { Dressler-Verlag) en Heidelberg, } \\
\text { Gaisbergstrasse } 55\end{array}$ \\
\hline $\begin{array}{l}1900- \\
1934\end{array}$ & & $\begin{array}{l}\text { Restauración de Marksburg, antes } \\
\text { Braubach am Rhein }\end{array}$ \\
\hline 1901 & Nace su hijo Klaus & \\
\hline $\begin{array}{l}1901- \\
1908\end{array}$ & & $\begin{array}{l}\text { Restauración de Hohkönigsburg (en } \\
\text { francés, HautKoenigsbourg) en Alsacia }\end{array}$ \\
\hline $\begin{array}{l}1901- \\
1902\end{array}$ & & $\begin{array}{l}\text { Villa Cornelio Meyer en } \\
\text { Berlín-Grunewald }\end{array}$ \\
\hline 1903 & & $\begin{array}{l}\text { Monumento a los caídos en } 1870- \\
1871 \text { Braubach }\end{array}$ \\
\hline c. 1904 & & $\begin{array}{l}\text { Dependencias a Villamartin en } \\
\text { Neubabelsberg }\end{array}$ \\
\hline 1904 & & Villa Remmer en Berlín-Grunewald \\
\hline $\begin{array}{l}1904- \\
1906\end{array}$ & & $\begin{array}{l}\text { Ampliación de los castillos } \\
\text { Landonvillers en Lorraine }\end{array}$ \\
\hline
\end{tabular}




\begin{tabular}{|c|c|c|}
\hline $\begin{array}{l}1905- \\
1906\end{array}$ & & $\begin{array}{l}\text { Restauración del salón de la iglesia } \\
\text { de Schloss Altenburg después de un } \\
\text { incendio }\end{array}$ \\
\hline $\begin{array}{l}1906- \\
1908\end{array}$ & & $\begin{array}{l}\text { Construcción de Hakeburg en } \\
\text { Kleinmachnow }\end{array}$ \\
\hline $\begin{array}{l}1906- \\
1908\end{array}$ & & $\begin{array}{l}\text { Trabajos de restauración y edificios } \\
\text { auxiliares en el Grodziec }\end{array}$ \\
\hline $\begin{array}{l}1906- \\
1925\end{array}$ & & $\begin{array}{l}\text { Restauración y ampliación de } \\
\text { Schloss Neuenstein (Hohenlohe) }\end{array}$ \\
\hline $\begin{array}{l}1908- \\
1909\end{array}$ & & Villa Ribbeck en Berlín-Grunewald \\
\hline 1909 & $\begin{array}{l}\text { Se traslada a vivir al Marksburg en } \\
\text { Braubach }\end{array}$ & \\
\hline 1909 & Ciudadano honorífico de Braubach & \\
\hline $\begin{array}{l}1909- \\
1925\end{array}$ & & $\begin{array}{l}\text { Restauración y construcción de varios } \\
\text { edificios nuevos en laVeste Coburg }\end{array}$ \\
\hline c. 1910 & & Casa Lucke en Schlettstadt \\
\hline $\begin{array}{l}1911- \\
1912\end{array}$ & & Restauración de Schloss Sallgast \\
\hline $\begin{array}{l}1911- \\
1913\end{array}$ & & Finalización del castillo wommen \\
\hline 1912 & & Restauración del castillo Langenau \\
\hline $\begin{array}{l}1912- \\
1913\end{array}$ & & $\begin{array}{l}\text { Bankhaus von der Heydt (el llamado } \\
\text { "Kleisthaus") en Berlín, Mauerstrasse } 53\end{array}$ \\
\hline $\begin{array}{l}1912- \\
1914\end{array}$ & & $\begin{array}{l}\text { Construcción del castillo de } \\
\text { Wartburg-Gasthofs en Eisenach }\end{array}$ \\
\hline $\begin{array}{l}1912- \\
1914\end{array}$ & & Restauración del castillo Czocha \\
\hline $\begin{array}{l}1913- \\
1914\end{array}$ & & $\begin{array}{l}\text { Restauración y ampliación de Schloss } \\
\text { Gross Leuthen }\end{array}$ \\
\hline $\begin{array}{l}1913- \\
1916\end{array}$ & & Fürstliches Hoftheater en Detmold \\
\hline $\begin{array}{l}1914- \\
1915\end{array}$ & & $\begin{array}{l}\text { Ampliación de la sede Allianz } \\
\text { Versicherungs-AG en Berlín }\end{array}$ \\
\hline $\begin{array}{l}1914- \\
1915\end{array}$ & & $\begin{array}{l}\text { Plan de desarrollo para la reconstrucción } \\
\text { de Neidenburg (Prusia Oriental) }\end{array}$ \\
\hline $\begin{array}{l}1914- \\
1925\end{array}$ & & $\begin{array}{l}\text { Reconstrucción libre del castillo } \\
\text { Kipfenberg }\end{array}$ \\
\hline
\end{tabular}




\begin{tabular}{|c|c|c|}
\hline $\begin{array}{l}1920- \\
1945\end{array}$ & $\begin{array}{l}\text { Preside la Deutsche } \\
\text { Burgenvereinigung }\end{array}$ & \\
\hline 1920 & & $\begin{array}{l}\text { Proyecto de restauración del castillo } \\
\text { Neuhausen }\end{array}$ \\
\hline $\begin{array}{l}1920- \\
1921\end{array}$ & & Restauración del castillo Kaulsdorf \\
\hline $\begin{array}{l}1920- \\
1923\end{array}$ & & Restauración de Schloss Eichicht \\
\hline $\begin{array}{l}1921- \\
1923\end{array}$ & & $\begin{array}{l}\text { Restauración del Castillo Scharfens- } \\
\text { tein después de un incendio }\end{array}$ \\
\hline $\begin{array}{l}1921- \\
1923\end{array}$ & & Restauración del castillo de Creuzburg \\
\hline $\begin{array}{l}1922- \\
1927\end{array}$ & & $\begin{array}{l}\text { Construcción de la Hornburg sobre los } \\
\text { restos existentes }\end{array}$ \\
\hline $\begin{array}{l}1922- \\
1928\end{array}$ & & Ampliación del castillo Heimhof \\
\hline $\begin{array}{l}1922- \\
1935\end{array}$ & & $\begin{array}{l}\text { Restauración del castillo en } \\
\text { Gröditz Weissenberg }\end{array}$ \\
\hline $\begin{array}{l}1926- \\
1927\end{array}$ & & Casa Petschull en Diez an der Lahn \\
\hline 1927 & $\begin{array}{l}\text { Presidente del Comité de Diseño } \\
\text { Urbano del Gran Berlín }\end{array}$ & \\
\hline 1928 & $\begin{array}{l}\text { Miembro fundador de los Amigos de } \\
\text { Plassenburg }\end{array}$ & \\
\hline $\begin{array}{l}1929- \\
1930\end{array}$ & & Restauración de la mansión Gollwitz \\
\hline 1931 & $\begin{array}{l}\text { Delega su estudio de arquitectura a } \\
\text { su hijo Fritz y comienza la redacción } \\
\text { de Der Wehrbau Europas im Mitte- } \\
\text { lalter }\end{array}$ & \\
\hline $\begin{array}{l}1931- \\
1932\end{array}$ & & $\begin{array}{l}\text { Castle Rock ( Arenfels ) a Hoenningen } \\
\text { am Rhein }\end{array}$ \\
\hline $\begin{array}{l}1933- \\
1935\end{array}$ & & Villa Mühlberg en Ohrdruf \\
\hline 1945 & Muere en el Marksburg en Braubach & \\
\hline
\end{tabular}

Una de las obras más relevantes, en lo arquitectónico y en lo ideológico, es la restauración del castillo alsaciano de Hohkönigsburg; Haut-Koeningsbourg en francés (fig. 2). En 1899 el emperador Guillermo II de Hohenzollern encarga las obras de restauración a Bodo 


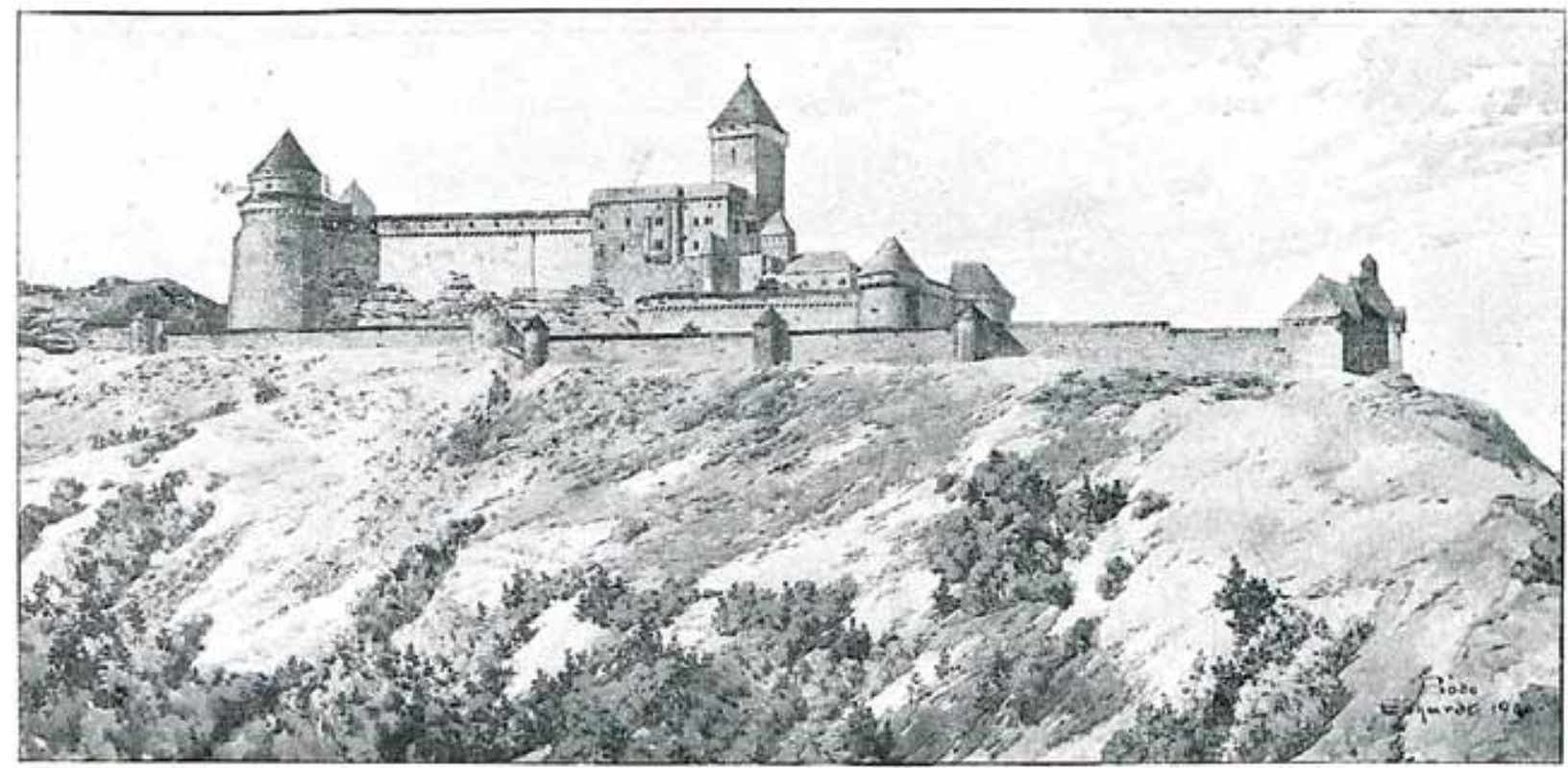

Figura 2. Vista del castillo de Hohkönigsburg (Ebhardt 1900-1901, 148, fig. 1)

Ebhardt del que se consideraba una atalaya germánica en Alsacia y que debía glorificar los antiguos valores de la monarquía, la aristocracia y la burguesía medieval conservados a través de la idea de elevar, con esta restauración, un gran monumento para la gloria de la dinastía legítima del Imperio: los Hohenzollern. ${ }^{5}$ La idea del proyecto, altamente politizado, es devolver el castillo en ruinas a su estado de apogeo en el siglo XV, incluyendo la restauración de los espacios interiores y el mobiliario. ${ }^{6}$ Las obras se acompañan de trabajos arqueológicos que catalogan todos los restos encontrados entre los escombros y los movimientos de tierras necesarios para las nuevas construcciones que proyecta Ebhardt. Se abre una nueva cantera y se traza una vía férrea para el transporte de la piedra, de igual manera que se construye una estación de bombeo para el agua. Los trabajos continúan durante siete años hasta que un lluvioso 13 de mayo de 1908 el emperador inaugura de nuevo el castillo entre burlas y

5. Taylor, op. cit. C. O’ Farrell, Hohkönigsburg und der Wohnbau auf der Burg im 19. Jahrhundert, Munich, GRIN Verlag, 2009.

6. J.-J. Schwien, y J.-C. Dauk, "Des Tierstein à Bodo Ebhardt. Le mobilier archéologique des fouilles du Haut-Koenigsbourg (1900-1908)", en Cahiers alsaciens d'archéologie d'art et d'histoireSociété pour la conservation des monuments historiques d'Alsace, 2005, 133-168. 
críticas, ya que fue tildado como una «ópera bufa medieval». ${ }^{7}$ El castillo volverá a pertenecer a Francia tras el Tratado de Versalles.

Ebhardt defiende el empleo del método científico como base de la intervención arquitectónica ante el monumento. De hecho, en 1900-1901 publica un artículo sobre las artes y oficios en la época de la construcción de Hohkönigsburg explicados a través del material arqueológico rescatado y catalogado: armas y herramientas de metal, piezas de bronce, herraduras, estribos, herramientas de la construcción (picos, azuelas, punteros), restos de piezas del hogar (morillo, placas de horno), herrajes, candados, llaves y cerraduras de puertas y ventanas, piezas decorativas de cobre repujado y proyectiles (fig. 3 ).

El hecho de que la restauración de Hohkönigsburg esté promovida por la figura del emperador se inscribe en el contexto de su situación geográfica y de la importancia histórica que tuvo. El castillo forma parte del sistema defensivo del alto Rin. El río Rin ha sido protagonista histórico de una lucha por su control y de ahí la importancia que se dio a la restauración de los castillos que lo jalonan como inherentes a la imagen nacional. Ebhardt veía en la línea defensiva del Rin los vestigios de la amenaza de las hordas enemigas que podían de nuevo descender sobre el pueblo alemán. La destrucción del patrimonio militar medieval no sólo ofrecía una visión aterradora sobre los hechos ocurridos antaño, sino que, para Ebhardt, deben fomentar una llamada al «odio, la venganza y la batalla hasta el final». ${ }^{8}$ Tras el panorama desolador dejado por la destrucción de la Gran Guerra, Ebhardt radicaliza su nacionalismo.

Ebhardt tiene un concepto de la restauración arquitectónica por el que el edificio debe volver a un estado original; o un estado concreto de su historia, aunque haya que edificar nuevas partes, en la corriente de Viollet-le-Duc. De hecho, Ebhardt se apoya en los estudios de Viollet-le-Duc sobre el mobiliario y la arquitectura medieval para sus reinterpretaciones. ${ }^{9}$

Las ideas del arquitecto francés parecen pesar sobre el pensamiento y la actitud restauradora de Bodo Ebhardt. Viollet-le-Duc había realizado una gran aportación al estudio de la arquitectura militar medieval, tanto desde los artículos del Dictionnaire raisonné sur l'architecture française du XIe au XVIe siècle como desde las publicaciones monográficas sobre la arquitectura militar y las restauraciones de los castillos y conjuntos de Coucy, Pierrefonds, Roquetaillade y Carcassonne. El pensamiento positivista y funcionalista de Viollet-leDuc le hace comprender la obra fortificada como una respuesta inteligente y efectiva ante las fuerzas activas del arte de la guerra. Entiende que el objetivo de la construcción de muralla y torres es la defensa y la vigilancia frente al ataque con máquinas y tropas; bajo este enfoque, las formas y los aspectos constructivos de la arquitectura militar - que descompone como si

7. E. Castellani Zahir, "Echt falsch und doch shön alt: die Wiederherstellung der Hohkönigsburg im Elsass 1900 bis 1908”, Zeitschrift für Schweizerische Archäologie und Kunstgeschichte, 54, nº 2, 1997, 141-152.

8. S. Goebe, The Great War and Medieval Memory. War, Remembrance and Medievalism in Britain and Germany, 1914-1940, Cambridge, Cambridge University Press, 2009, 175.

9. Viollet-le-Duc estudia al detalle los aspectos formales de los muebles: E.E. Viollet-le-Duc, Dictionnaire raisonné du mobilier français de l'epoque carlovingienne à la renaissance, 6 vols., París 1865-1875. B. Ebhardt, "Das Kunstgewerbe auf der Hohkönigsburg “, Das Kunstgewerbe in Elsaß-Lothringen, 1, 1900-1901, 154. 


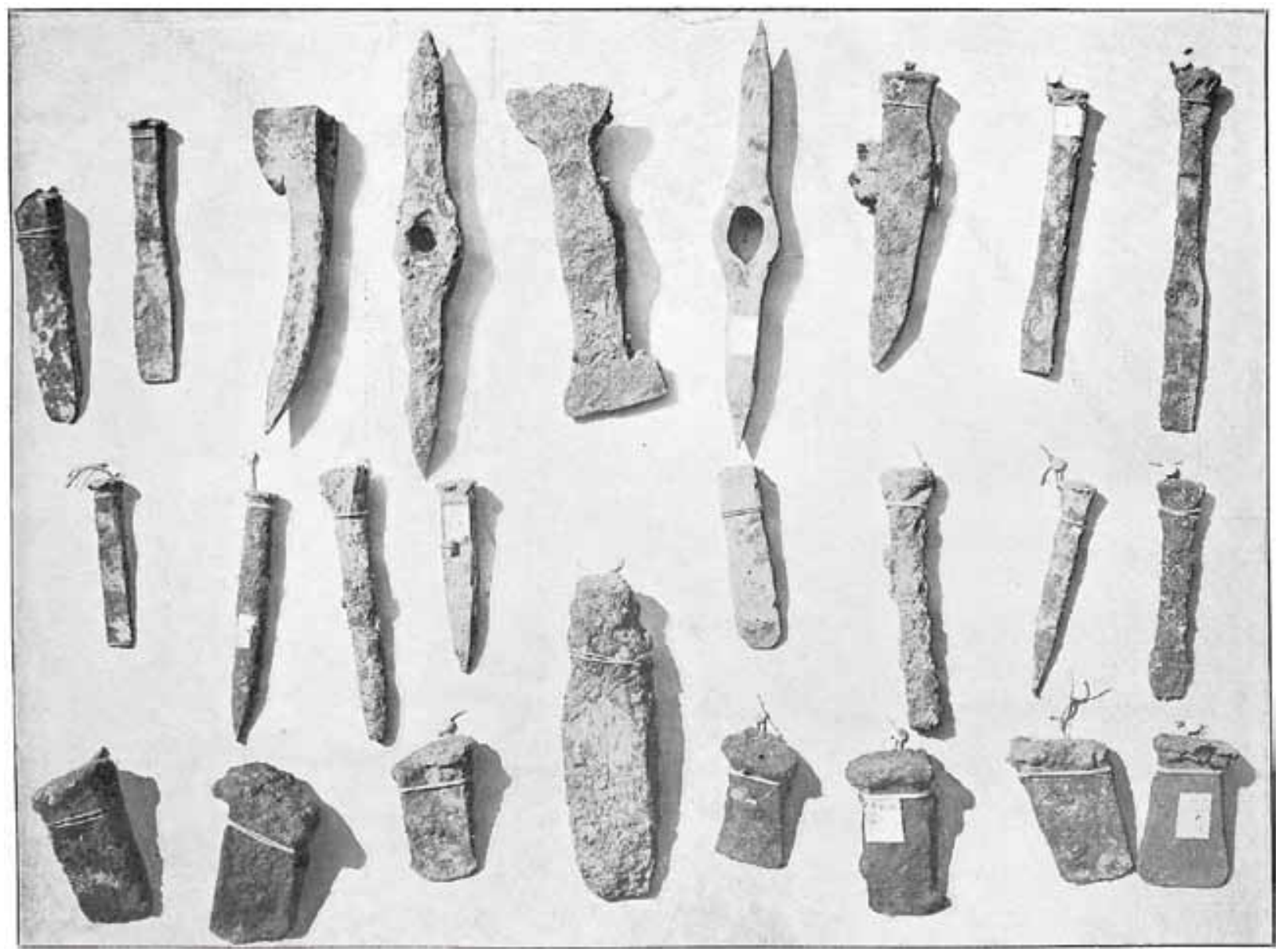

Figura 3. Herramientas de cantería rescatadas durante los trabajos previos a la restauración del castillo Hohkönigsburg (Ebhardt, 1900-1901: 153, fig. 13)

diseccionara un ser vivo para estudiar sus órganos y las relaciones entre ellos- derivan del desarrollo poliorcético.

No obstante el rigor científico del trabajo de investigación con el que Viollet-le-Duc arranca la labor de intervención sobre un monumento, no aboga por, únicamente, conservarlo como propone la teoría de Ruskin, sino que va a buscar un estado idealizado que puede no haber existido jamás y «en el estilo que le es propio». Este estado idealizado se consigue gracias a la labor no sólo de restauración arquitectónica, sino también mobiliaria y decorativa. ${ }^{10}$

10. R. di Fusco, "Viollet-le-Duc y Ruskin", en La idea de Arquitectura, historia de la crítica desde Viollet-leDuc a Perisco, Barcelona, 1976; P. Gout, Viollet-le-Duc: sa vie, son oeuvre, sa doctrine, Paris 1914; N. Pevsner, 
Viollet-le-Duc había definido la restauración de un edificio de la siguiente manera: «restaurar un edificio, no es mantenerle, repararle o rehacerle, es restablecerle en un estado completo que puede no haber existido nunca en un momento dado». ${ }^{11}$ Esta intervención se apoya en un profundo y científico conocimiento del edificio y debe realizarse con el mayor respeto y cuidado. Sin embargo, esta actitud puede flexibilizarse ante la necesidad de darle una nueva vida al monumento: «el arquitecto encargado de una restauración de un edificio tiene que conocer las formas, los estilos a los que pertenece este edificio y la escuela de donde viene, aún más, si es posible, tiene que conocer su estructura, su anatomía, temperamento, porque antes de todo tiene que hacerlo vivir». Para Viollet-le-Duc, el arquitecto restaurador debe garantizar que el edificio restaurado tenga una nueva vida, con un uso lo más cercano posible a su función original. Para este fin ha de ser respetuoso, si bien ante los deseos y exigencias de los clientes (en el caso de Pierrefonds, el emperador) el restaurador cede espacio al proyectista

Viollet-le-Duc intervino en los castillos de Coucy (1856-1861), Pierrefonds (1858-1879), Roquetaillade (1864) y la ciudad de Carcassonne (1846-1879), donde parece querer volver a poner en uso una arquitectura tan esencialmente funcional como la militar. En 1857 Napoleón III encarga a Viollet-le-Duc la reconstrucción del castillo de Pierrefonds (siglo XIV, comprado en 1813 por Napoleón I) para destinarlo a residencia imperial. ${ }^{12}$ Lo que empieza con una restauración "sobre el papel" se acrecienta con los caprichos del emperador y el alojamiento de las colecciones reales. Las obras adquieren un ritmo activo y se proyectan nuevas estancias y soluciones como la terminación de la capilla sin una base científica sólida que arme los argumentos. ${ }^{13}$

Presente la influencia de Viollet-le-Duc, Bodo Ebhardt considera que se puede detener el avance de la ruina con la completa restauración del edificio a un momento de su pasado en el que todos sus elementos estén acordes en el estilo llegando a producir la copia más parecida al original. ${ }^{14}$ Esto le valió muchas críticas por parte de los opositores

2010. Ruskin and Viollet-le-Duc: Englishness and Frenchness in the appreciation of Gothic architecture, Londres 1969.

11. «restaurer un édifice, ce n'est pas l’entretenir, le réparer ou le refaire, c'est le rétablir dans un état complet qui peut n’avoir jamais existé à un moment donné». E.E. Viollet-le-Duc, Dictionnaire raisonné sur l'architecture française du XIe au XVIe siècle, 10 vols., París 1854-1968, VIII, 14.

12. En este sentido, la restauración encargada por Guillermo II del castillo de Hohkönigsburg por parte de Ebhardt puede entenderse como un reflejo de la de Pierrefonds por parte de Viollet-le-Duc a través del delirio de Luis II de Baviera quien, tras su visita a Pierrefonds en 1867, forja la idea de Neuschwandstein. Este conocido castillo neomedieval concebido para fomentar la creatividad wagneriana comenzó su construcción en 1869 bajo el proyecto del arquitecto Eduard Riedel (subrogado a los deseos del monarca) y del diseñador escénico de la Corte Christian Jank. L. de Mora Figueroa, "En torno a Viollet-le-Duc y la arquitectura militar medieval", Gades, 1, 21-24.

13. P. Araguas, "Viollet-le-Duc restaurador de edificios militares: entre teoría y práctica", en Simposio internacional «Arquitectura fortificada». Conservación, restauración y uso de los castillos, Valladolid 2005, 219-241.

14. Taylor, op. cit., 242-243. 
a la restauración monumental, como Riegl, que busca el estado de ánimo real de la ruina. Ebhardt, de alguna manera, perseguía la aspiración de la exactitud histórica y la autenticidad en el estilo. Este pensamiento le llevó a inventar de manera libre con el fin de completar una imagen casi escenográfica de la arquitectura militar medieval. Ya en sus primeras publicaciones deja claro este punto de vista sobre la ruina. En Deutsche Burgen (1898) propone y aboga por la reconstrucción de la ruina. ${ }^{15}$ En 1899 publica un breve artículo en Die Denkmalpflege titulado «Wie sollen wir unsere Burgruinen erhalten?» — « Cómo vamos a conservar nuestras ruinas?» (1899) — ${ }^{16}$ en el que sostiene la importancia de los estudios científicos como base del plan de trabajo de intervención sobre la ruina. A través de sus artículos en la revista Der Burgwart (entre 1908 y 1933) que él mismo fundara - hoy, Burgen und Schlösser - sigue defendiendo esta actitud.

Para Ebhardt, la tarea de la conservación consiste en proteger el monumento por su valor histórico, como icono patriótico apoyado en valores sociales y políticos conservadores. ${ }^{17} \mathrm{Y}$ es este valor histórico el que justifica la reconstrucción, sobre la ruina, del edificio añadiendo - e incluso creando- las partes que faltan siempre con el apoyo de un conocimiento científico de la arquitectura militar medieval en cuanto a sus factores paisajísticos o sistémicos, arquitectónicos, poliorcéticos y constructivos. El conocimiento científico apoya las decisiones estéticas. El carácter de vivienda (si bien fortificada) que es el castillo justifica la incorporación del proyecto del mobiliario, la decoración, las telas e incluso la música en la restauración historicista que promueve Ebhardt.

Precisamente esta actitud frente al monumento, el cual trata de devolver a una vida pasada gloriosa, es la diana de las críticas de Alois Riegl, quien en su Neue Strömungen in der Denkmalpflege - Nuevas corrientes en la práctica de la preservación de los monumentos (1905) - ${ }^{18}$ se lamenta que Ebhardt rellena con nuevas construcciones las lagunas que la ruina había dejado del edificio original. Estos nuevos miembros añadidos carecen del valor histórico en sí mismo que sí tiene la ruina. En este texto, Riegl compara los métodos académicos del análisis cuidadoso y el estudio de los restos conservados de Dehio - «conservar, no restaurar»-con la búsqueda del «memorial» por parte de Ebhardt. Riegl defiende que la asociación de ideas respecto de la ruina genera en nosotros una sensación de placer de manera que lo inventado en la restauración, como material anacrónico, causa molestia.

\section{Ebhardt y la investigación científica sobre los castillos}

Esta actividad constructora y restauradora no sólo contemplaba la intervención patrimonial, sino que se dedicó a investigar y publicar sobre los castillos alemanes y de toda Europa. Ebhard considera que hay una finalidad didáctica y pedagógica en la investigación histórica

15. B. Ebhardt, Deutsche Burgen, Berlín, 1898.

16. B. Ebhardt, "Wie sollen wir unsere Burgruinen erhalten?” Die Denkmalpflege, 1 1899, 54-55 y 62-63.

17. Taylor, op. cit., 242.

18. A. Riegl, "Neue Strömungen in der Denkmalpflege", Mitteilungen der K. K. Zentralkommission für Erforschung und Erhaltung der Kunst- und historischen Denkmale, 3, n 4, 1905, 85-104. 
y en la publicación científica, si bien la enseñanza que pretende inculcar —especialmente a los jóvenes - se reviste de pasiones nacionalistas. ${ }^{19}$

En 1899 funda la Deutsche Burgenvereinigung - la Asociación Alemana de los Castillos- con el fin de conservar el patrimonio defensivo alemán, con sede en el Marksburg de Braubach. Logra involucrar a buena parte de la nobleza que aún era la propietaria de los castillos. Ebhardt presidió la Asociación desde 1920 hasta su muerte. Gran viajero, recorrió Europa dibujando, tomando datos y levantamientos con los que fue publicando diversos libros sobre los castillos en Alemania (1898-1908), ${ }^{20}$ Italia (1909-27), ${ }^{21}$ Francia y Bélgica (1915) ${ }^{22}$ y España (1934). ${ }^{23}$ Algunos de estos viajes estuvieron patrocinados por la figura del emperador Guillermo II, a quien dedicó su obra Deutsche Burgen (1908). En 1901 le becó para un viaje de estudios por Austria, Suiza y el sur de Alemania con el fin de estudiar y dibujar los castillos. ${ }^{24}$

Estos textos se reescribieron, compendiaron y ampliaron en la voluminosa obra -748 páginas, 783 figuras y 128 láminas- Der Wehrbau Europas im Mittelalter (1939-1958). Esta obra de madurez - en la que ya no se aprecia el chauvinismo tan presente en sus primeras obras- comprende los castillos de los Países Bajos, Inglaterra, Irlanda, Escocia, Francia, Alemania (donde incluye a Silesia, Prusia, las actuales Repúblicas Bálticas y Austria), Suiza, España, Portugal, Italia, Suecia, Noruega, Finlandia, los Sudetes, Bohemia y Moravia, la «ex-Polonia» (sic), Hungría, Eslovaquia, Transilvania (la región sajona de Rumanía), Croacia y Eslavonia, Bosnia y Herzegowina, Servia, Rumanía, Bulgaria, la costa adriática, Grecia y Creta, para finalizar con los castillos de los estrechos del Bósforo y Dardanelos, en la Turquía europea.

No obstante, sus estudios científicos están profundamente pervertidos por su reaccionario nacionalismo y la amplificación de los sentimientos hacia los objetos de su estudio, esto es: los castillos, que son entendidos como «valorables herencias de nuestro pueblo». ${ }^{25}$ Sus ideas nacionalistas y filonazis empañan su investigación con la concepción de que la construcción castrense europea emana, biológicamente, del pueblo alemán dado que éste conquistó Europa en la Alta Edad Media. Este pensamiento nacionalista y racista se enmarca en la búsqueda de un internacionalismo del castillo alemán. ${ }^{26}$ Como advierte Taylor, «sus dibujos y pinturas eran minuciosos y precisos, y el tono de sus publicaciones entusiasta y sincero, aunque su enfoque era paradójico. Tenía una imagen idealizada sobre los castillos medievales y sobre sus propietarios, estando bastante dispuesto a que la imaginación invalidara a la precisión» (fig. 4). ${ }^{27}$

19. Taylor, op. cit., 247.

20. B. Ebhardt, Deutsche Burgen als Zeugen deutscher Geschichte, Berlín, F. Zillessen, 1908.

21. B. Ebhardt, Die Burgen Italiens. 6 vols Berlín, E. Wasmuth, 1909-1927.

22. B. Ebhardt, Krieg und Baukunst in Frankreich und Belgien, Berlín, Burguerlag, 1915.

23. B. Ebhardt, Spanische Burgenfahrt 1930. Ein Reisebericht, Marksburg Burgverlag, 1934.

24. Taylor, op. cit., 244-245.

25. B. Ebhardt, Die Burgen des Elsaß, Berlín, 1904, 22. Citado por Taylor, op. cit., 367, nota 53.

26. F. Link, "The Internationalism of German Castle Research: Bodo Ebhardt, His European Network, and the Construction of 'Castle Knowledge", Public Archaeology 8, n 4, 2009, 325-350.

27. «His drawings and paintings were thorough and precise and the tone of his publications enthusiastic and sincere, but his approach was paradoxical. He had an idealiazed view of medieval castles and their owners and was too willing to let imagination override precision», Taylor, op. cit., 243 


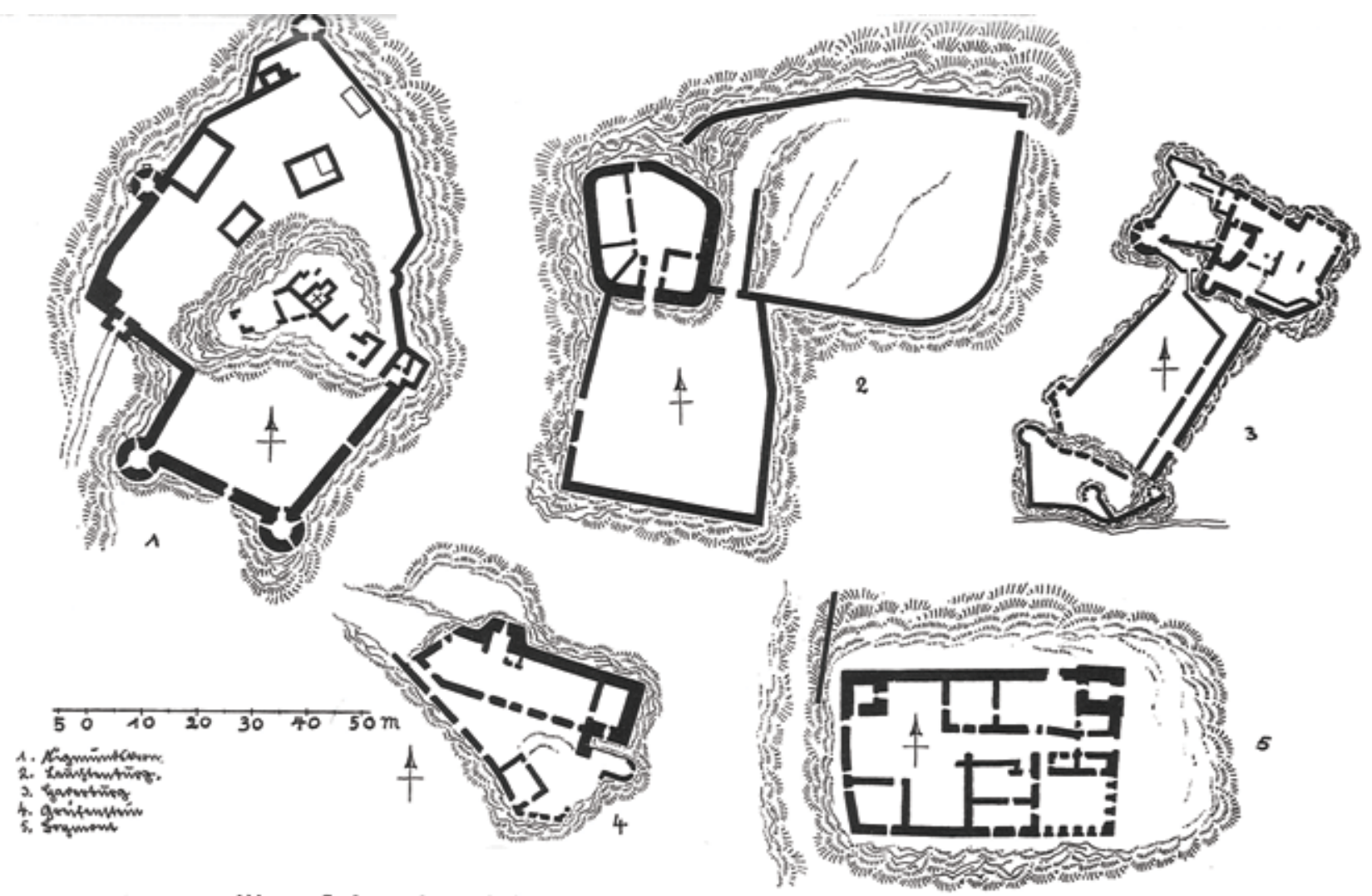

Abb. 702. Grofien. u. formvergl. Grdr. Tiroler Burgen. B. E. n. Weingartner u. elg. Aufn., Grdr, etwa 1:1000.

Figura 4. Lámina de comparación a la misma escala de las plantas de diversos castillos del Tirol (Ebhardt 1939-1958, 585, fig. 702)

Sus trabajos de investigación están repletos de dibujos a pluma o a lápiz, croquis de detalles, precisas plantas, secciones y alzados a escala y fotografías tomadas por él mismo. Cuando no ha levantado él mismo el monumento que está describiendo y ha de utilizar una fuente secundaria, siempre redibuja el plano citando la fuente de la que se ha servido. Sus publicaciones gozan de una gran unidad gráfica por este motivo, por conservar el criterio y el estilo e incluir siempre la escala del dibujo. Por este motivo, a pesar de la intencionada perspectiva racista en su historia de la fortificación europea, sus dibujos y mapas gozan de una magnífica precisión y tienen un gran valor en la investigación castellológica actual.

Ebhardt, a pesar de la intencionalidad patriótica con que piensa y escribe, constituye un exponente del desarrollo de las modernas disciplinas de la Historia y la Arqueología. ${ }^{28}$

28. Taylor, op. cit., 247. 

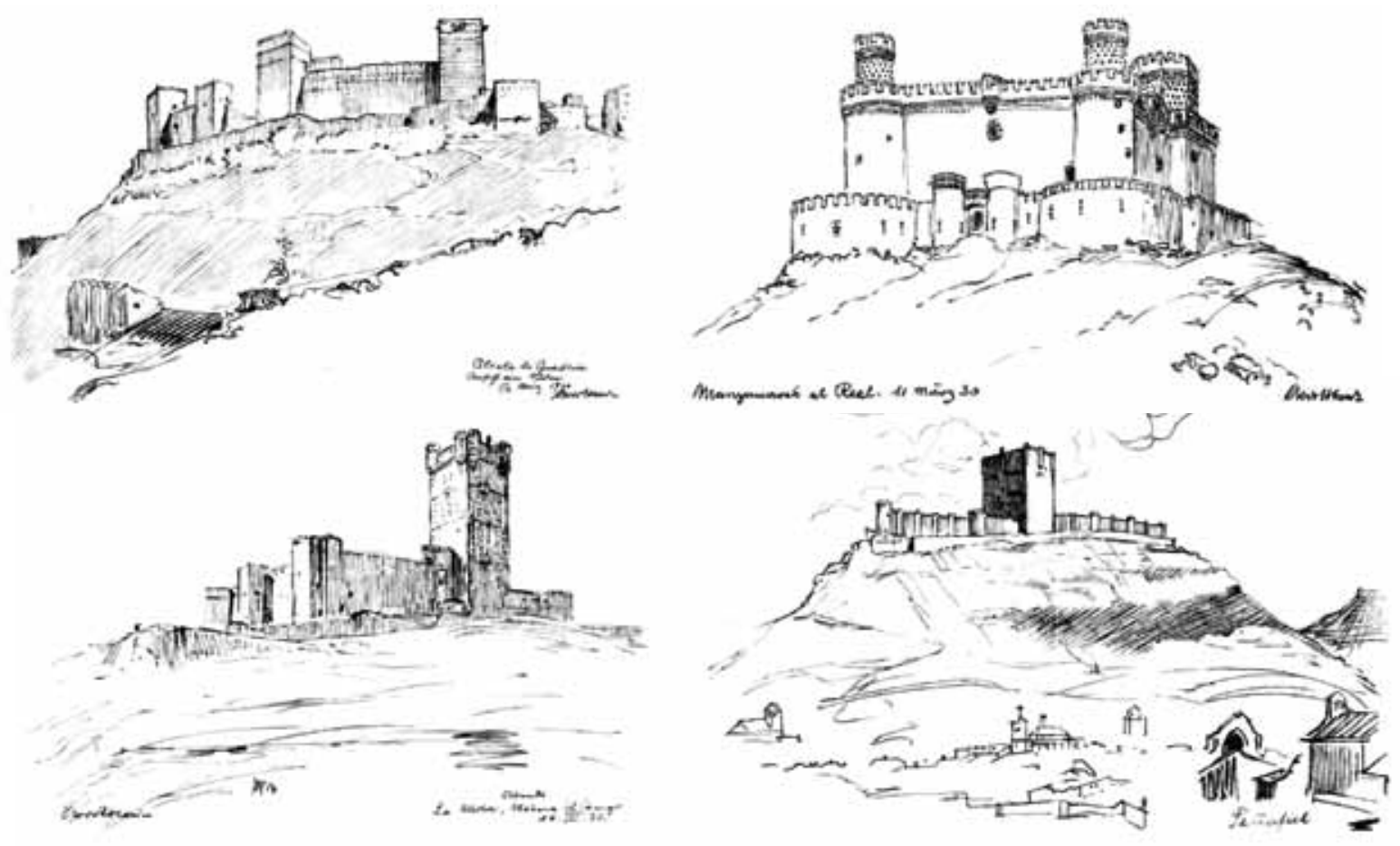

Figura 5. Dibujos a lápiz de los castillos de Alcalá de Guadaira (t. 93), Manzanares el Real (t. 107), La Mota de Medina del Campo (t. 121) y Peñafiel (t. 123-124)

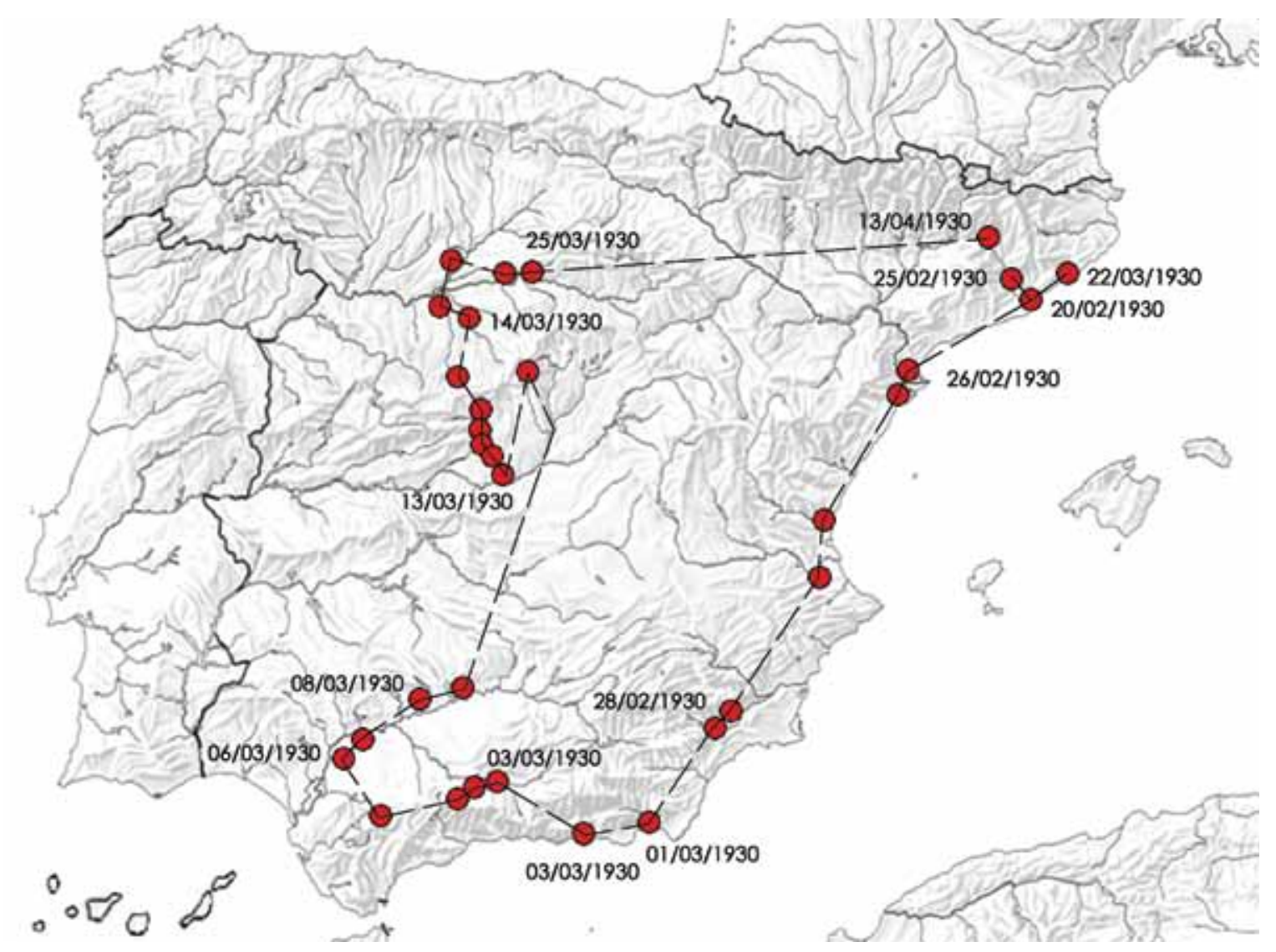

Figura 6. Mapa del itinerario que recorrió Bodo Ebhardt por España entre febrero y abril de 1930 


\section{El viaje por España de 1930}

Bodo Ebhardt realizó un viaje por España entre febrero y abril de 1930 en el cual documentó un significativo número de castillos y fortalezas. Además de la toma de fotografías, Ebhardt llevó un cuaderno de dibujo en el que con lápiz o pluma tomó vistas y detalles en precisos y preciosos dibujos. En 1934 publicó Spanische Burgenfahrt 1930. Ein Reisebericht von Bodo Ebhardt, Architekt -Paseo por los castillos españoles 1930. Cuaderno de viaje de Bodo Ebhardt, arquitecto- en el que incluye sus dibujos y finaliza con un apéndice fotográfico mientras describe su viaje (fig. 5).

Llama la atención sobre el hecho de que los acontecimientos históricos que ocurrieron en la España medieval difieren notablemente de los de la Europa central por el elemento musulmán. Ebhardt comienza señalando que a pesar de la separación casi física con Europa por el mar y los Pirineos, en España han confluido diversas civilizaciones e influencias como los fenicios y los musulmanes desde África, los romanos desde el Mediterráneo y los godos desde las tierras del norte. Todas estas influencias son las que configuran la forma, los tipos y la construcción de los castillos españoles. ${ }^{29}$

Ebhardt entra en España desde Perpignan, tras haber atravesado Francia. De hecho, los primeros dibujos que aparecen en su cuaderno de viajes son de Tournon sur Rhone, Pont St. Esprit y Perpignan. Ebhardt se queja de las malas carreteras francesas y alaba la mejora de las carreteras españolas, más anchas. Entra por La Junquera y envía una carta a Espinosa de los Monteros (a quien suponemos como su contacto en España) en donde da respuesta a todas las preguntas que le habría planteado sobre el viaje con una única y feliz respuesta: «Nur sind wir wirklich in Spanien!» - «iYa estamos de verdad en España!»—.${ }^{30}$ Desde Cataluña recorrió el Levante y Murcia para llegar hasta Andalucía para, después, visitar algunos castillos relevantes de Toledo, Madrid, Segovia y Valladolid. Ebhardt fecha casi todos sus dibujos, como se puede apreciar en la Tabla 2. Esto nos permite reconstruir el itinerario que recorrió en su paseo por España (fig. 6).

\section{Tabla 2. Figuras en Spanische Burgenfahrt (1934) con indicación del tipo de dibujo y la fecha}

\begin{tabular}{|l|l|l|l|l|}
\hline $\begin{array}{l}\text { Figura } \\
\text { (pág) }\end{array}$ & Castillo & Provincia & Tipo de dibujo & Fecha \\
\hline 9 & Almería & Almería & planta general de la ciudad & s.f. \\
\hline 21 & $\begin{array}{l}\text { Tournon an der } \\
\text { Rhone }\end{array}$ & Francia & vista a lápiz & s.f. \\
\hline
\end{tabular}

29. Ebhardt, op. cit., 1934, 5.

30. Ebhardt, op. cit., 24. 


\begin{tabular}{|c|c|c|c|c|}
\hline 23 & Pont St. Esprit & Francia & vista a lápiz & $20 / 02 / 1930$ \\
\hline 31 & $\begin{array}{l}\text { Perpignan, Tor } \\
\text { zu Unfer lieben } \\
\text { Frau }\end{array}$ & Francia & vista a lápiz & $20 / 02 / 1930$ \\
\hline 34 & Arenys de Mar & Barcelona & Vista a lápiz & $22 / 03 / 1930$ \\
\hline 38 & Papiol & Barcelona & vista a lápiz & 1930 \\
\hline 39 & $\begin{array}{l}\text { Castelbell de } \\
\text { Cardona }\end{array}$ & Barcelona & vista a lápiz & $25 / 02 / 1930$ \\
\hline 41 & $\begin{array}{l}\text { Castelbell de } \\
\text { Cardona }\end{array}$ & Barcelona & $\begin{array}{l}\text { detalles de una ventanas } \\
\text { geminadas y un arco }\end{array}$ & s.f. \\
\hline 43 & Solsona & Lérida & vista a lápiz & $13 / 04 / 1905$ \\
\hline 44 & Solsona & Lérida & detalle de un capitel & s.f. \\
\hline 49 & Tortosa & Tarragona & detalle de una columna & feb-30 \\
\hline 51 & Ulldecona & Tarragona & vista a lápiz & 26/02/1930 \\
\hline 55 & Alacuás & Valencia & vista a tinta & $20 / 02 / 1930$ \\
\hline 60 & Játiva & Valencia & planta & s.f. \\
\hline 65 & Aledo & Murcia & $\begin{array}{l}\text { croquis acotado de la } \\
\text { planta }\end{array}$ & $28 / 02 / 1930$ \\
\hline 66 & Aledo & Murcia & $\begin{array}{l}\text { croquis acotado de la } \\
\text { sección }\end{array}$ & $28 / 02 / 1930$ \\
\hline 67 & Aledo & Murcia & $\begin{array}{l}\text { detalle acotado de una } \\
\text { ménsula }\end{array}$ & s.f. \\
\hline 68 & Lorca & Murcia & $\begin{array}{l}\text { detalle de una ventana } \\
\text { ojival }\end{array}$ & $28 / 02 / 1930$ \\
\hline 69 & Lorca & Murcia & detalle de unas ménsulas & $28 / 02 / 1930$ \\
\hline 70 & Lorca & Murcia & detalle de una puerta & $28 / 02 / 1930$ \\
\hline 73 & Almería & Álmería & vista a lápiz & 1930 \\
\hline 74 & Almería & Álmería & detalle de las almenas & $01 / 03 / 1930$ \\
\hline 75 & Almería & Álmería & vista a lápiz & 1930 \\
\hline 79 & Loja & Granada & vista a lápiz & 03/03/1930 \\
\hline 81 & pájaros en Loja & Granada & vista a lápiz & s.f. \\
\hline 82 & $\begin{array}{l}\text { Archidona, } \\
\text { viviendas tradi- } \\
\text { cionales }\end{array}$ & Málaga & vista a lápiz & 03/03/1930 \\
\hline 83 & Antequera & Málaga & detalle de una ventana & 03/03/1930 \\
\hline 86 & $\begin{array}{l}\text { Zahara (de la } \\
\text { Sierra) }\end{array}$ & Cádiz & vista a lápiz & 1930 \\
\hline
\end{tabular}




\begin{tabular}{|c|c|c|c|c|}
\hline 92 & $\begin{array}{l}\text { Alcalá de Gua- } \\
\text { daira }\end{array}$ & Sevilla & detalle de unos escudos & 06/03/1930 \\
\hline 98 & $\begin{array}{l}\text { Almodóvar (del } \\
\text { Río) }\end{array}$ & Córdoba & detalle de una pechina & s.f. \\
\hline 99 & El Carpio & Córdoba & detalle de una ventana & 08/03/1930 \\
\hline 100 & El Carpio & Córdoba & vista del interior & 1930 \\
\hline 101 & El Carpio & Córdoba & $\begin{array}{l}\text { detalle de una ventana } \\
\text { geminada }\end{array}$ & 08/03/1930 \\
\hline 103 & $\begin{array}{l}\text { Manzanares el } \\
\text { Real }\end{array}$ & Madrid & detalle de unos matacanes & s.f. \\
\hline 113 & Maqueda & Toledo & $\begin{array}{l}\text { croquis acotado de una } \\
\text { puerta }\end{array}$ & $13 / 03 / 1930$ \\
\hline 116 & $\begin{array}{l}\text { Ávila, calle de } \\
\text { Pedro Dávila }\end{array}$ & Ávila & vista a tinta & s.f. \\
\hline 118 & Coca & Segovia & detalle de unas garitas & $14 / 03 / 1930$ \\
\hline 124 & Haza & Burgos & vista a lápiz & $25 / 03 / 1930$ \\
\hline Lámina & Castillo & Provincia & Tipo de dibujo & Fecha \\
\hline 34 & $\begin{array}{l}\text { Torre de los } \\
\text { Encantados, } \\
\text { Arenys de Mar }\end{array}$ & Barcelona & Vista a lápiz & $22 / 03 / 1930$ \\
\hline 40 & Cardona & Barcelona & Vista a lápiz & $23 / 03 / 1930$ \\
\hline 40 & Cardona & Barcelona & Vista a lápiz & $23 / 03 / 1930$ \\
\hline 40 & Cardona & Barcelona & Vista a lápiz & $23 / 03 / 1930$ \\
\hline 40 & Cardona & Barcelona & Vista a lápiz & 23/03/1930 \\
\hline 55 & Alacuás & Valencia & Vista a lápiz & $26 / 02 / 1930$ \\
\hline 59 & Játiva & Valencia & Vista a lápiz & $27 / 02 / 1930$ \\
\hline 63 & $\begin{array}{l}\text { Alicante, cas- } \\
\text { tillo de Santa } \\
\text { Bárbara }\end{array}$ & Alicante & Vista a lápiz & 1930 \\
\hline 65 & Aledo & Murcia & Vista a lápiz & $28 / 02 / 1930$ \\
\hline 73 & Almería & Almería & Vista a lápiz & $01 / 03 / 1930$ \\
\hline 77 & La Rábita & Granada & Vista a lápiz & 1930 \\
\hline $83-84$ & Antequera & Málaga & Vista a lápiz & 03/03/1930 \\
\hline 86 & $\begin{array}{l}\text { Zahara (de la } \\
\text { Sierra) }\end{array}$ & Cádiz & Vista a lápiz & 07/03/1930 \\
\hline
\end{tabular}




\begin{tabular}{|c|c|c|c|c|}
\hline 87 & $\begin{array}{l}\text { Zahara (de la } \\
\text { Sierra) }\end{array}$ & Cádiz & Vista a lápiz & 07/03/1930 \\
\hline 93 & $\begin{array}{l}\text { Alcalá de Gua- } \\
\text { daira }\end{array}$ & Sevilla & Vista a lápiz & 07/03/1930 \\
\hline 84 & Carmona & Sevilla & Vista a lápiz & 06/03/1930 \\
\hline 95 & Carmona & Sevilla & Vista a lápiz & 06/03/1930 \\
\hline 96 & $\begin{array}{l}\text { Córdoba, } \\
\text { alcázar }\end{array}$ & Córdoba & Vista a lápiz & 08/03/1930 \\
\hline $99-101$ & El Carpio & Córdoba & Vista a lápiz & 08/03/1930 \\
\hline 107 & $\begin{array}{l}\text { Manzanares el } \\
\text { Real }\end{array}$ & Madrid & Vista a lápiz & $11 / 03 / 1930$ \\
\hline 109 & $\begin{array}{l}\text { Toledo, castillo } \\
\text { de San Servan- } \\
\text { do }\end{array}$ & Toledo & Vista a lápiz & s.f. \\
\hline 111 & Guardamur & Toledo & Vista a lápiz & $12 / 03 / 1930$ \\
\hline 112 & Barcience & Toledo & Vista a lápiz & $13 / 03 / 1930$ \\
\hline 112 & Escalona & Toledo & Vista a lápiz & $13 / 03 / 1930$ \\
\hline 112 & Escalona & Toledo & Vista a lápiz & $13 / 03 / 1930$ \\
\hline 113 & Maqueda & Toledo & Vista a lápiz & $13 / 03 / 1930$ \\
\hline 114 & $\begin{array}{l}\text { San Martín de } \\
\text { Valdeiglesias }\end{array}$ & Madrid & Vista a lápiz & $13 / 03 / 1930$ \\
\hline 121 & $\begin{array}{l}\text { Medina del } \\
\text { Campo, castillo } \\
\text { de la Mota }\end{array}$ & Valladolid & Vista a lápiz & $14 / 03 / 1930$ \\
\hline 122 & Fuensaldaña & Valladolid & Vista a lápiz & 1930 \\
\hline $\begin{array}{l}123- \\
124\end{array}$ & Peñafiel & Valladolid & Vista a lápiz & s.f. \\
\hline
\end{tabular}

Los datos, levantamientos, anotaciones y detalles serán muy útiles en la redacción del capítulo sobre los castillos españoles en su Der Wehrbau Europas im Mittelalter, donde vuelve a incluir algunos de ellos o de las fotografías mientras que otros son redibujados.

Además de las vistas y detalles de los castillos españoles, el libro está salpicado de letras capitales y pequeños y simpáticos apuntes como dibujos de unos pájaros, un botijo, unas casas tradicionales o las dos calaveras - cristiana y musulmana- yaciendo juntas en un campo de batalla con que se cierra la obra (fig. 7). 

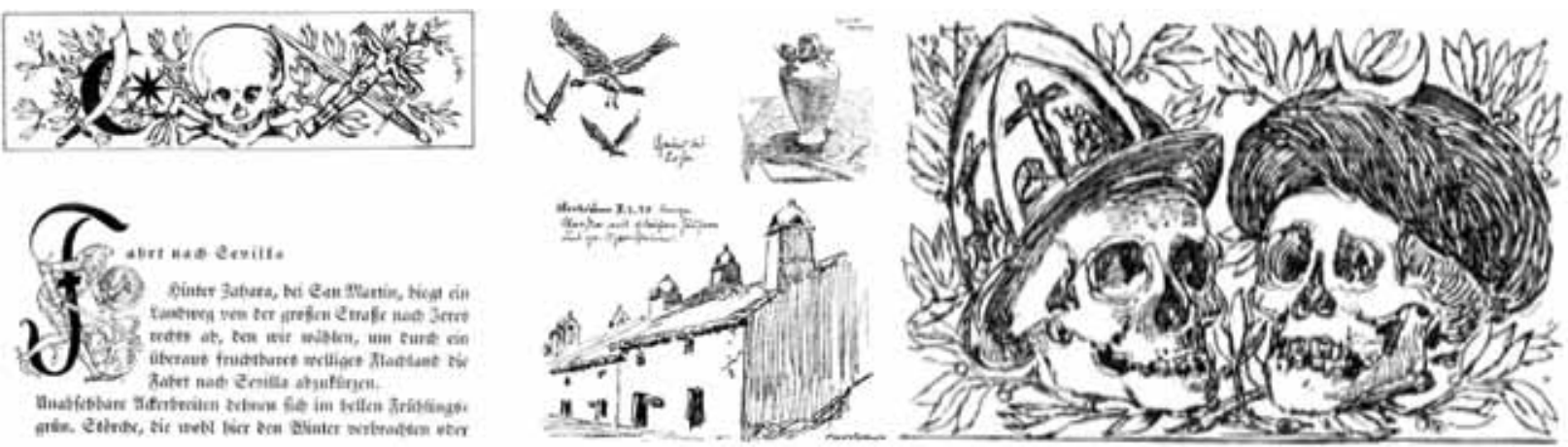

Figura 7. Algunos dibujos secundarios: calavera con dos tibias con que se abre la descripción el itinerario (p. 10), la letra capital «F» con un Don Quijote entre ella en el capítulo sobre la excursión por Sevilla (p. 90), unos pájaros en Loja (p. 81), un botijo (p. 110), arquitectura tradicional en Archidona (p. 82) y dos calaveras que yacen juntas en un supuesto campo de batalla caracterizadas con atributos cristianos y musulmanes respectivamente (p. 154)

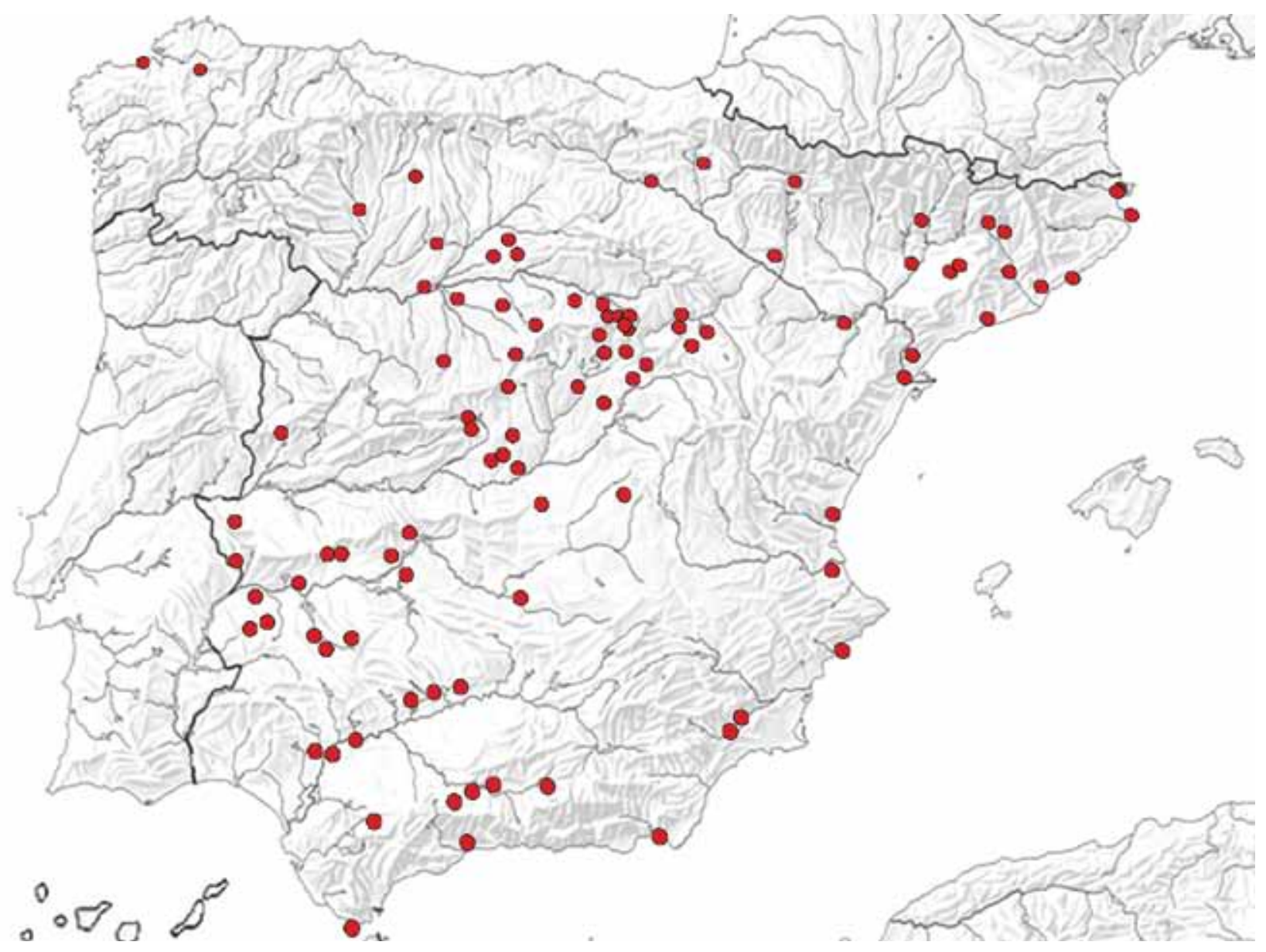

Figura 8. Mapa de situación de los castillos citados en Der Wehrbau Europas im Mittelalter 


\section{Los castillos españoles en Der Wehrbau Europas im Mittelalter}

La enciclopédica obra de Ebhardt sobre la fortificación medieval europea contiene un amplio capítulo -127 páginas, 32 láminas de fotografías, 11 de dibujos y 105 figuras de plantas, alzados y secciones - dedicado a los castillos españoles, con un considerable número de elementos estudiados, mucho mayor que el de los que visitó años antes en su 'paseo' de 1930 (fig. 8). Para reelaborar sus primeras impresiones publicadas en el Spanische Burgenfahrt de 1930 (publicado en 1934), Ebhardt se vale de fuentes bibliográficas, tanto españolas como alemanas. En algunos casos, su viaje le nutrió de suficientes datos como para dibujar unos levantamientos descriptivos de algunos castillos (fig. 9). No obstante, Ebhardt realiza una completa investigación bibliográfica en los años posteriores. El rigor científico es exquisito en lo referente a la cita de las fuentes y de la información que emplea de otros autores, lo cual permite hacer un completo análisis historiográfico de su obra. Tras su viaje por España, Ebhardt está al tanto de las novedades bibliográficas, que no duda en utilizar. Tal es el caso del Castillos de Guadalajara de Layna Serrano (1933), ${ }^{31}$ de donde extrae abundante material gráfico que reelabora en el marco de su tradicional hacer con respecto al lenguaje gráfico uniforme de la obra (fig. 10). El alemán se nutre de obras generales sobre la castellología española, como los libros de Paz Espeso (1914), ${ }^{32}$ Lampérez (1922), ${ }^{33}$ Sainz de Robles (1932) ${ }^{34}$ y Sarthou Carreres (1933). ${ }^{35}$

Otras fuentes que emplea para documentar los castillos de diversas provincias son los respectivos catálogos monumentales, como el Catálogo Monumental de la provincia de Zamora, Catálogo Monumental de la provincia de León, Catálogo Arqueológico y Artístico de la Provincia de Sevilla, Catálogo Monumental de la provincia de Cádiz o el de Badajoz. ${ }^{36}$ Entre las fuentes que Ebhardt sigue para argumentar los acontecimientos históricos destacan $L a$ España del Cid de Menéndez Pidal (1929), ${ }^{37}$ las Noticias de los arquitectos y arquitectura, ${ }^{38}$ la Crónica general de España ${ }^{39}$ o fuentes históricas como la Historia della perdita e riacquisto della Spagna occupata da mori de Bartolomeo de Rogatis (1660). ${ }^{40}$

31. F. Layna Serrano, Castillos de Guadalajara, Madrid, Nuevas Gráficas, 1933.

32. J. Paz Espeso, Castillos y fortalezas del reino, Madrid, Imprenta de la Revista de Archiveros, Bibliotecarios y Museos, 1914.

33. V. Lampérez y Romea, Arquitectura Civil Española de los siglos I al XVIII, Madrid, Ediciones Giner, [1922] 1993.

34. F.C. Sainz de Robles, Castillos en España. Su historia, su arte, sus leyendas, Barcelona, Iberia, 1932.

35. C. Sarthou Carreres, Castillos de España, Madrid, Espasa Calpe, [1933] 1979.

36. J.R. Mélida, Catálogo Monumental de España, Provincia de Badajoz. 3 vols Madrid, Ministerio de Instrucción Pública y Bellas Artes, 1907-1910.

37. R. Menéndez Pidal, La España del Cid, Madrid, Plutarco, 1929.

38. E. Llaguno y Amirola, Noticias de los arquitectos y arquitectura de España desde su restauración, Madrid, Imprenta Real, 1829.

39. J.D.de la Rada y Delgado, Crónica general de España, ó sea Historia ilustrada y descriptiva de sus provincias, sus poblaciones más importantes y posesiones de ultramar, Madrid, Rubio, Grillo y Vittori, 1869.

40. B.de Rogartis, Historia della perdita e riacquisto della Spagna occupata da mori Venecia, appresso i Guerigli, 1660. 

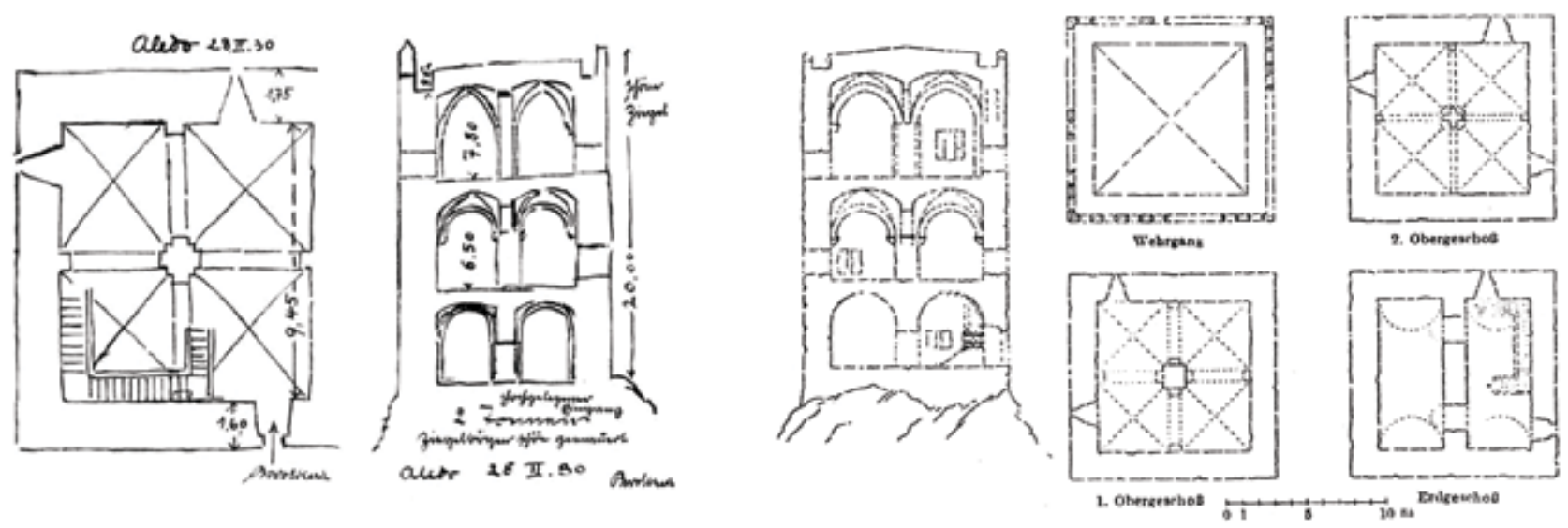

Figura 9. Croquis en planta y sección de la fortaleza de Aledo (Murcia) tomados por Bodo Ebhardt durante su viaje por España en 1930 y publicados en su libro de 1934 (pp. 65-66). Plantas y sección redibujadas sobre estos datos publicadas en Der Wehrbau Europas im Mittelalter (p. 122, fig. 100)
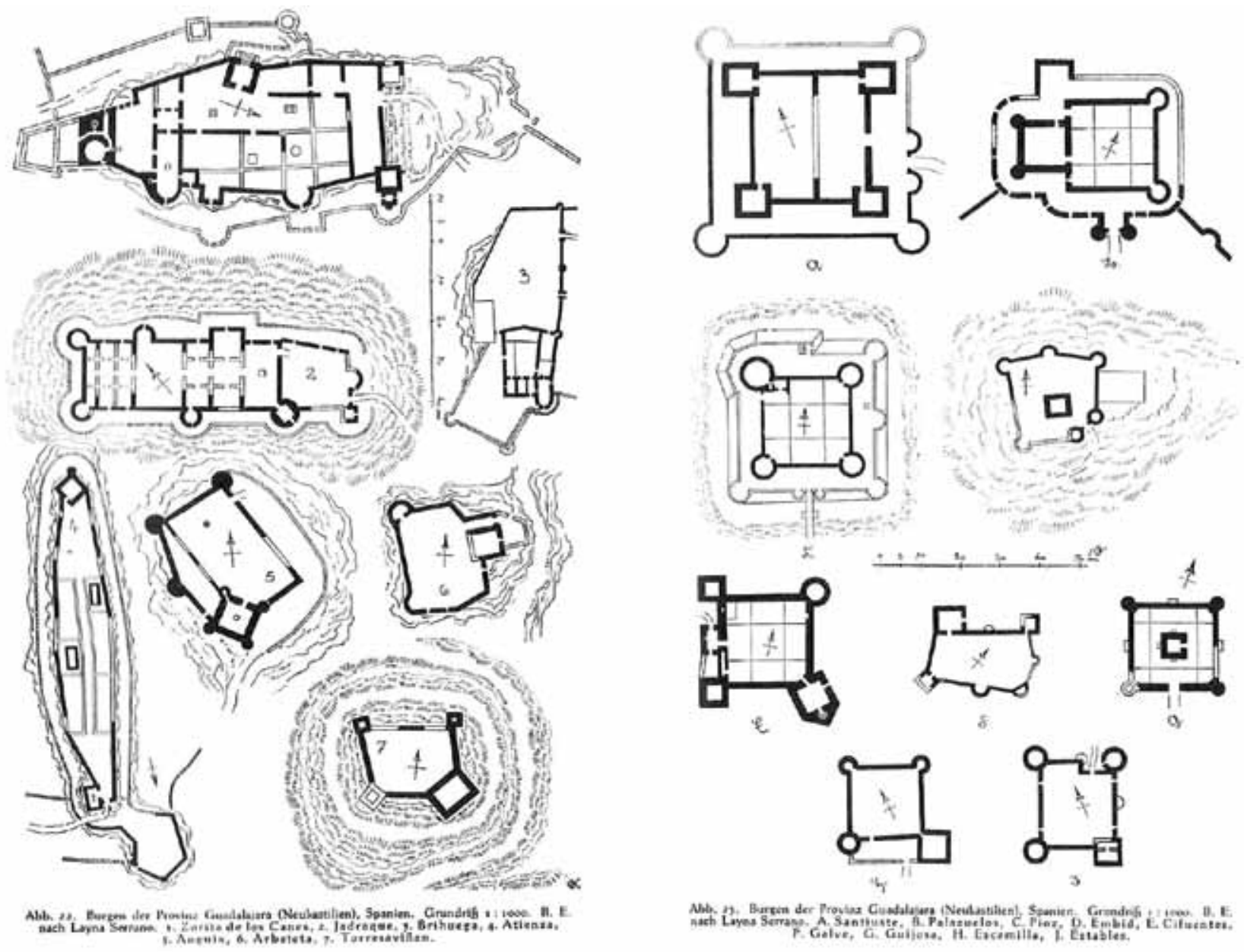

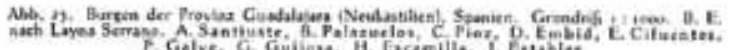

Figura 10. Láminas con las plantas de los castillos de Guadalajara en Ebhardt (1939-1958: 42-43, figs. 22-23), tomadas de las que dibuja Layna Serrano (1933) de los mismos castillos 
Ebhardt también acude a la literatura alemana sobre la historia y el arte de España, en donde destacan las obras de Schirrmacher (1861), ${ }^{41}$ Schubert (1908), ${ }^{42}$ Rigel (1819-1821), ${ }^{43}$ Kuhn $(1925){ }^{44}$ o Jürgens (1926). ${ }^{45}$ Las memorias de viajes del excursionismo científico ha sido siempre una fuente de información; tal es el caso de su propio libro sobre el viaje por España de 1930 que cita en varias ocasiones. En este contexto, Ebhardt hace uso no sólo de este tipo de obras como el viaje desde Gibraltar a Málaga de Carter (1779), ${ }^{46}$ sino que también cita en varias ocasiones el Boletín de la Sociedad Española de Excursiones, el Boletín de la Sociedad Castellana de Excursiones, el Anuari de la Associació d'excursions Catalana, el Boletín del Turismo o Guía oficial de Toledo e incluso la Guía Michelin.

Por último, Ebhardt recurre a diversas monografías sobre castillos específicos para obtener información y elaborar sus dibujos y planos: Contreras $(1878)^{47}$ para la Alhambra de Granada, Navarro (1895) ${ }^{48}$ para Escalona y Maqueda, Gil $(1905)^{49}$ para el castillo de Loarre y el Alcázar de Segovia, Torres Balbás para el alcázar de Córdoba, Casanova para el Castillo de Almodóvar del Río, Capdevilla para el castillo de Maldà, (Jeroni) Martorell, Arquitecto Conservador de Zona de Cataluña para el castillo de Peralada, (Francisco) Tettamancy Gastón para el castillo de Villalba en Lugo, Ricardo Martín para el castillo de Aulencia, (Sainz de) Robles para el castillo de Belmonte, (E. H. v.) Hausler para el plano general de La Coruña, o v. Fürstenhoff para el castillo de Ager.

El capítulo sobre los castillos españoles en Der Wehrbau Europas im Mittelalter sigue una estructura muy distinta de la de su anterior cuaderno de viajes. Comienza con un epígrafe dedicado a explicar la evolución histórica y el desarrollo de los castillos en España, en donde se aprecia su pensamiento sobre el peso del elemento godo que pervivió sin interrupción en el norte de España tras la ocupación árabe y que se mantiene y difunde durante la reconquista, «en las guerras de religión» por la «fuerza de voluntad de la raza».50

A este capítulo introductorio le sigue otro breve epígrafe en el que desglosa algunos detalles o elementos arquitectónicos y poliorcéticos de los castillos españoles, en cuanto a la

41. F.W. Schirrmacher, H. Schäfer, y F. Wilhelm Lembke, Geschichte von Spanien, Gotha, Bei Friedrich Andreas Bertes, 1861.

42. O. Schubert, Geschichte des barock in Spanien, Esslingen, Paul Neff, 1908.

43. F.X. Rigel, Der siebenjährige Kampf auf der Pyrenäischen Halbinsel vom Jahre 1807 bis 1814 Besonders meine eigenen Erfahrungen in diesem Kriege nebst Bemerkungen über das spanische Volk und Land, Darmstadt, in Comm. bey Heyer und Leste, 1819-1821.

44. A. Kuhn, Das alte Spanien, Berlín, Verlag Neufeld und Henius, 1925.

45. O. Jürgens, y W. Giese, Spanische Städte: Ihre bauliche entwickklungound Angestaltung, Hamburgo, Verlag L. Friederichsen, 1926.

46. F. Carter, Reise von Gibraltar nach Málaga in Jahr, 1772., Leipzig, Crusius, 1779.

47. R. Contreras, Estudio descriptivo de los monumentos árabes de Granada, Sevilla y Córdoba o sea La Alhambra, el Alcázar y la Gran Mequita de Occidente, Madrid, Imprenta y litografía de A. Rodero, 1878.

48. F.B. Navarro, "Fortalezas y castillos de la Edad Media (Maqueda y Escalona)", Boletín de la Sociedad Española de Excursiones, 3, n 25, 1895, 1-15.

49. I. Gil, El castillo de Loarre y el Alcázar de Segovia: capítulos de un libro inédito, Burgos, Burgos, 1905. 50. Ebhardt, op. cit., 1939-1958, 5. 
forma de las torres, los aspectos residenciales, las formas de las galerías, escaleras, capillas, puertas, puentes, ventanas, calabozos, almenas e incluso la calefacción y el abastecimiento de aguas. A continuación, tras explicar las distintas formas de las plantas de los castillos españoles, sigue un desarrollo geográfico por los castillos de Castilla la Vieja, Castilla la Nueva, Andalucía, Extremadura, León, Galicia, Aragón, Navarra, País Vasco, Cataluña, Valencia, Murcia y Baleares. Estas consideraciones y análisis por elementos arquitectónicos así como la clasificación regional son de clara influencia de la obra de Lampérez. ${ }^{51}$ Finaliza el extenso capítulo sobre los castillos españoles con unas conclusiones generales donde incide en el hecho diferenciador entre la España musulmana (al sur) y la España gótico-germana (al norte).

La figura de Ebhardt no ha tenido, en la castellología española, un peso relevante. Esta situación quizá se deba a su visión pangermánica sesgada e intencionada y a que, respecto de los grandes compendios castellológicos españoles y monografías específicas no ofrezca datos nuevos. Basado en su conocimiento de primera mano - si bien durante una estancia corta y en un reducido, pero selecto, número de castillos por él visitados en 1930- y al trabajo de documentación bibliográfica que arma su capítulo en Der Wehrbau Europas im Mittelalter, Ebhardt ofrece un análisis general por regiones (en la línea de Lampérez) en donde trata de rescatar el, para él, importante peso godo-germánico que subyace en los tipos y la construcción de los castillos medievales de «la España cristiana germánica». El hecho constructivo le sirve para argumentar esta idea, ya que, en una imagen reduccionista y errónea, señala que en el sur de la Península - con mayor influencia musulmana - se construyen los castillos con tapia de tierra mientras que los castillos septentrionales - donde permanece, se mantiene, resiste y termina por expandirse el sustrato cultural visigodo- se levantan las torres y murallas con fábrica de piedra al modo europeo.

Ya lo había dejado expresado en su primera publicación sobre los castillos españoles: «la técnica oriental de construcción con tapia de tierra todavía permanece en el sur de Andalucía y Murcia, frente a la construcción con piedra (sillería y mampostería) o mixta (en el castillo de Escalona, por ejemplo) de las regiones septentrionales (Castilla, Aragón, Cataluña y otras)». ${ }^{52}$

\section{Conclusiones}

Bodo Ebhardt es un arquitecto restaurador que aboga por incluir el método de documentación histórica en las intervenciones con el fin de devolver las ruinas - provocadas, según él, por el ataque de las fuerzas enemigas que siguen latentes allende las fronteras - a un estado primigenio de esplendor en el que la arquitectura, las artes aplicadas, la decoración y el mobiliario responden a una reconstrucción histórica altamente idealizada, politizada e

51. Lampérez, op. cit.

52. «Der technik des Orients, mit Lehmbeton zu bauen (tapia), die im Süden in Andalusien, Murcia usm. noch hente an gemandt wird, steht die Steinbautechnik (Duader und Bruch Steinbauten) des Nordens (Kastiliens, Aragons, Kataloniens, u.a.) gegenüber (Siehe die Mischung an der Burg Escalona)», Ebhardt, op. cit., 1934, 6 . 
intencionada. Por este motivo, estudia la castellología medieval europea desde este punto de vista científico, si bien se permite licencias a la hora de argumentar el peso germánico en la tipología arquitectónica y en la construcción fortificada medieval. Sus publicaciones son el fruto de sus viajes y sus investigaciones, actividades paralelas a su actividad restauradora. Ebhardt mantiene y defiende una teoría de la restauración no exenta de crítica. Riegl no comparte la restauración histórica y estilística de Ebhardt que le lleva a completar la ruina con nuevas construcciones.

Ebhardt sostiene un pensamiento altamente racista sobre la construcción fortificada medieval, en donde el peso gótico-germánico impregna las formas, los elementos y la historia de los castillos europeos, entre ellos los españoles. No obstante, las particulares características que presenta la fortificación medieval española frente a la coetánea europea - en cuanto a la presencia y la influencia de elemento islámico durante ocho siglos- hacen que Ebhardt argumente este punto.

La autoridad y el crédito de Ebhardt es mayor fuera que dentro de España y no es infrecuente encontrar referencias a su obra y a sus estudios en los compendios castellológicos o las obras de referencia internacionales. No obstante, se hace necesario una revisión de su estudio sobre los castillos españoles, así como una traducción y análisis crítico de estas obras. El material gráfico por sí mismo posee un gran valor de conjunto y no está exento de rigor. Con esta aportación se pretende rescatar una figura esencial en la historiografía castellológica medieval.

\section{Apéndice: bibliografía de Bodo Ebhardt}

B. Ebhardt, Deutsche Burgen, Berlín, 1898.

B. Ebhardt, "Wie sollen wir unsere Burgruinen erhalten?" Die Denkmalpflege, 1, 1899, 54-55 y 62-63.

B. Ebhardt, "Forschungen und Ausgrabungen auf der fränkischen Salzburg bei Neustadt an der Saale", Der Burgwart, 1, 1899-1900, 18-19.

B. Ebhardt, "Das Kunstgewerbe auf der Hohkönigsburg “, Das Kunstgewerbe in Elsaß-Lothringen, 1, 1900-1901, 148-160.

B. Ebhardt, "Der Kaiser auf der Hohköningsburg", Der Burgwart, 9, no. 5, 1904, 105-112.

B. Ebhardt, Die Burgen des Elsaß, Berlín, 1904.

B. Ebhardt, "Burgen der Hohenzollern", en P. Seidel (Ed.), Hohenzollern-Jahrbuch. Forschungen und Abbildungen zur Geschichte der Hohenzollern in Brandenburg-Preussen, Berlin: Giesecke and Devrient, 1905, 252-299.

B. Ebhardt, Ueber Verfall, Erhaltung und Wiederherstellung von Baudenkmalen mit Regeln für praktische Ausführungen, Berlín, Ebhardt, 1905.

B. Ebhardt, "Die wiederauferstandene Hohköningsburg", Der Burgwart, 9, n 4, 1908, 73-74.

E. Müsebeck, y B. Ebhardt, Schloß und Dorf Londonvillers. Besitz des Landrats, Berlín, Feyl, 1908.

B. Ebhardt, Der Väter Erbe. Beiträge zur Burgenkunde und Denkmalpflege. Aus Anlass des zehnjährigen Bestehens der Vereinigung zur Erhaltung deutscher Burgen, Berlín, 1909. 
B. Ebhardt, Die Burgen Italiens. 6 vols., Berlín, E. Wasmuth, 1909-1927.

B. Ebhardt, "Neuenstein “, Der Väter Erbe. Beiträge zur Burgenkunde und Denkmalpflege, 1909, 60-67.

B. Ebhardt, Deutsche Burgen als Zeugen deutscher Geschichte, Berlín, F. Zillessen, 1908.

B. Ebhardt, Der Einfluß des mittelalterlichen Wehrbaus auf den Städtebau Berlín, 1910.

B. Ebhardt, Vorschlag zu einem Bismarck-National-Denkmal auf der Elisenhöhe bei Bingerbrück, Berlín, 1910.

B. Ebhardt, Steinerne Zeugen: Wehrbauten Veronas, Berlín-Grunewald, 1911.

O.F. Hoppe, y B. Ebhardt, Stadt und Bad Mergentheim in Württemberg ed. A. Bofinger Stuttgart, 1911.

B. Ebhardt, Bericht über die Tätigkeit des Architekten-Ausschusses Gross-Berlin, gebildet im Jahre 1906 durch die Vereinigung Berliner Architekten und den Architekten-Verein zu Berlin, erst. in d. Mitgliederversammlg d. Vereinigg Berliner Architekten am 18. April 1912, Berlin-Grunewald, Burgverl., 1912.

B. Ebhardt, "Cesena”, Der Burgwart, 15, n 7, 1914, 145-150.

B. Ebhardt, Denkschrift über den Durchbruch Kurfürstendamm, Berlin, Burgverl., 1914.

B. Ebhardt, Der neue Wartburg-Gasthof, Berlin-Grunewald, Burgverl., 1914.

B. Ebhardt, Der Schloßbau : Eine Betrachtung über Neubau und Wiederherstellung von Schlössern, Berlin-Grunewald, Burgverl., 1914.

B. Ebhardt, "Die Sprache detscher Burgen", Der Burgwart, 16, nº 1, 1915, 2-10.

B. Ebhardt, Krieg und Baukunst in Frankreich und Belgien, Berlín, Burguerlag, 1915.

B. Ebhardt, "Alte Wehrbauten an den Küsen des östlichen Mittelmeeres», Der Burgwart, 17, n 2, 1916, 22-31.

B. Ebhardt, Burgen und Schlösser des Rhein-, Lahn- und Moseltales, Berlin, Deutscher Verl., 1917.

B. Ebhardt, Die Ebernburg bei Münster am Stein, Berlin-Grunewald, Burgverl, 1917.

B. Ebhardt, y C.A.C. Krollmann, Führer durch die Marksburg, Berlin-Grunewald, Burgverl., 1917.

B. Ebhardt, Deutschlands Helden eine Weihestätte? Eine Aufgabe für die deutsche Kunst BerlinGrunewald, Burgverl, 1918.

B. Ebhardt, "Feier des 25-jährigen Jubiläums der Vereinigung zur Erhaltung deutscher Burgen e.V., am 24. März", Der Burgwart, 25, nº 1-2, 1924, 9-30.

B. Ebhardt, Die zehn Bücher der Architektur des Vitruv und ihre Herausgeber seit 1484, BerlínGrunewald, 1918.

B. Ebhardt, "Die Sababurg und der Reinhardswald", Der Burgwart, 27,n 3/4, 1926, 40-45.

B. Ebhardt, Baudenkmale und Naturschönheiten im Reinhardswalde und im Kreise Hofgeismar: Ein Beitrag zur Platzfrage für das Reichsehrenmal, Berlín, Nauk'sche Buchdr., 1928.

B. Ebhardt, Burg Heimhof: ein Beitrag zur Geschichte des Hausener Tales bei Amberg in der Oberpfalz, Berlín, 1928.

B. Ebhardt, y B. Kühn, Städtebau-Ausschuß Groß-Berlin, Berlín-Grunewald, Burgverlag, 1929.

B. Ebhardt, Burg Heinehof im Hausener Tal bei Amberg in der Oberplatz, Berlin-Grunewald, BurgVerl., 1928.

B. Ebhardt, Schloß Arienfels bei Hönningen am Rhein, Marksburg bei Braubach, Burg-Verl., 1932.

B. Ebhardt, "Denkschrift über eine Reichshilfe zur Erhaltung deutscher Burgen und Burg-ruinen», Der Burgwart, 34 1933, 35-37.

B. Ebhardt, "Wasserburgen", Der Türmer. Monatsschrift für Gemüt und Geist, 1933, 521-528.

B. Ebhardt, y H.v.d. Gabelentz, Burgfest auf der Marksburg, Marksburg bei Braubach, Burg-Verl., 1933.

B. Ebhardt, Spanische Burgenfahrt 1930. Ein Reisebericht, Marksburg Burgverlag, 1934.

B. Ebhardt, Die Marksburg und ihre Geschichte Braubach, 1935.

B. Ebhardt, y F. Ebhardt, Handzeichnungen. Festschrift. Herausgegeben von der Vereinigung zur Erhaltung deutscher Burgen e.V., Berlín, Kunstwissenschaft, 1935. 
B. Ebhardt, Burg Trifels. Untersuchungen zur Baugeschichte, Braubach, 1938.

B. Ebhardt, Burg Trifels: Untersuchungen zur Baugeschichte, Marksburg 1938.

B. Ebhardt, Der Wehrbau Europas im Mittelalter. 3 vols Würzburg, Stollham, 1939-1958.

B. Ebhardt, "Tausendjährige Burgen bezeugen das Deutschtum im Elsass", Der Burgwart, 41, 1940, 1-8.

B. Ebhardt, "Zum 40jährigen Erscheinen des "Burgwart" 1899-1939. Ein Rückblick", Der Burgwart, 1938.

C. Michaelis, C.A.C. Krollmann, y B. Ebhardt, Rheinische Burgen: nach Handzeichnungen Dilichs (1607), Berlín, Franz Ebhardt, s.f. 